\title{
Bovine tuberculosis at the human-livestock-wildlife interface: Is it a public health problem in Tanzania? A review
}

\author{
Authors: \\ Bugwesa Z. Katale ${ }^{1,2}$ \\ Erasto V. Mbugi $^{1}$ \\ Sharon Kendal ${ }^{3}$ \\ Robert D. Fyumagwa² \\ Gibson S. Kibiki ${ }^{4}$ \\ Peter Godfrey-Faussett ${ }^{5}$ \\ Julius D. Keyyu² \\ Paul van Helden ${ }^{6}$ \\ Mecky I. Matee ${ }^{1}$ \\ Affiliations: \\ ${ }^{1}$ Department of Microbiology \\ and Immunology, Muhimbili \\ University of Health and \\ Allied Sciences, Tanzania \\ ${ }^{2}$ Tanzania Wildlife Research \\ Institute, Njiro, Arusha, \\ Tanzania \\ ${ }^{3}$ Centre for Emerging, \\ Endemic and Exotic disease, \\ Royal Veterinary College, \\ United Kingdom \\ ${ }^{4}$ Kilimanjaro Christian \\ Medical College, Kilimanjaro \\ Clinical Research Institute, \\ Tumaini University, Moshi, \\ Tanzania \\ ${ }^{5}$ Department of Infectious \\ and Tropical Diseases, \\ London School of Hygiene \\ and Tropical Medicine, \\ United Kingdom \\ ${ }^{6}$ DST/NRF Centre of \\ Excellence for Biomedical \\ Tuberculosis Research/MRC \\ Centre of Molecular and \\ Cellular Biology, Division \\ of Molecular Biology and \\ Human Genetics, Faculty of \\ Health Sciences, University \\ of Stellenbosch, \\ South Africa \\ Correspondence to: \\ Bugwesa Katale \\ Email: \\ bugwesa2002@yahoo.co.uk \\ Postal address: \\ PO Box 95001, Dar es Salaam, \\ Tanzania
}

Despite the apparent public health concern about Bovine tuberculosis (BTB) in Tanzania, little has been done regarding the zoonotic importance of the disease and raising awareness of the community to prevent the disease. Bovine tuberculosis is a potential zoonotic disease that can infect a variety of hosts, including humans. The presence of multiple hosts including wild animals, inefficient diagnostic techniques, absence of defined national controls and eradication programs could impede the control of bovine TB. In Tanzania, the diagnosis of Mycobacterium bovis in animals is mostly carried out by tuberculin skin testing, meat inspection in abattoirs and only rarely using bacteriological techniques. The estimated prevalence of BTB in animals in Tanzania varies and ranges across regions from $0.2 \%$ to $13.3 \%$, which is likely to be an underestimate if not confirmed by bacteriology or molecular techniques. Mycobacterium bovis has been detected and isolated from different animal species and has been recovered in 10\% of apparently healthy wildebeest that did not show lesions at post-mortem. The transmission of the disease from animals to humans can occur directly through the aerosol route and indirectly by consumption of raw milk. This poses an emerging disease threat in the current era of HIV confection in Tanzania and elsewhere. Mycobacterium bovis is one of the causative agents of human extra pulmonary tuberculosis. In Tanzania there was a significant increase (116.6\%) of extrapulmonary cases reported between 1995 and 2009, suggesting the possibility of widespread M. bovis and Mycobacterium tuberculosis infection due to general rise of Human Immunodeficiency virus (HIV). This paper aims to review the potential health and economic impact of bovine tuberculosis and challenges to its control in order to safeguard human and animal population in Tanzania.

\section{Introduction}

Mycobacterium tuberculosis, Mycobacterium bovis, Mycobacterium bovis BCG, Mycobacterium canettii, Mycobacterium africanum, Mycobacterium pinnipedii, Mycobacterium microti, Mycobacterium caprae, the dassie and the oryx bacillus, and the recently discovered Mycobacterium mungi are closely related species that form the M. tuberculosis complex (MTBC). Mycobacterium tuberculosis and $M$. bovis are the most important species in the complex which commonly cause human and animal tuberculosis (TB), with concomitant negative consequences for human and animal health and economic costs.

The probability of $M$. bovis transmission is more likely to occur between animals, particularly those in close contact such as herd animals (Grange \& Collins 1987). Humans can also be infected by $M$. bovis from contact with infected animals or animal products and the likelihood of infection and disease, as with human forms of TB are exacerbated by crowding and stress (Figueroa-Munoz \& Ramon-Pardo 2008). The transmission of M. bovis between humans or from humans to animals is very rare. Although the occurrence of $M$. bovis in humans is relatively minor compared to the burden from M. tuberculosis as far as we know, there is concern that the HIV and AIDS pandemic may have magnified this risk.

Transmission of $M$. bovis at the livestock-wildlife or human-animal interface occurs essentially because of overlap in their territories (Aranaz et al. 2004). Encroachment of wildlife sanctuaries by humans in Tanzania has increased the likelihood of this interaction and infection. Specifically, boundary regions areas in protected areas are used increasingly for grazing of livestock and agriculture and this corresponds with areas where the remaining population of wildlife has been concentrated by this land-use pressure (Etter et al. 2006). Factors as source of infection and

How to cite this proceeding: Katale, B.Z., Mbugi, E.V., Kendal, S., Fyumagwa, R.D., Kibik, G.S., Godfrey-Faussett, P. et al., 2012, 'Bovine tuberculosis at the human-livestock-wildlife interface: Is it a public health problem in Tanzania? A review', Onderstepoort Journal of Veterinary Research 79(2), Art. \#463, 8 pages. http://dx.doi.org/10.4102/ojvr.v79i2.463

Note: Proceedings of the Conference of the Southern African Centre for Infectious Disease Surveillance 'One Health' held at the National Institute for Communicable Diseases, Johannesburg, July 2011.

Copyright: ( 2012. The Authors. Licensee: AOSIS OpenJournals. This work is licensed under the Creative Commons Attribution License. 
transmissions of $M$. bovis include persistence of $M$. bovis in infected animals after death and survival of $M$. bovis in the environment (Aranaz et al. 2004).

It is not only domestic animals that can experience pathology from $M$. bovis, but a wide range of wild animal species in Africa, including lion (Panthera leo), buffalo (Syncerus caffer), wildebeest (Connochaetes taurinus), kudu (Tragelaphus strepsiceros), bushbuck (Tragelaphus scriptus), topi (Damaliscus lunatus) and a number of others (Cleveland et al. 2005). These animals can be a source of infection for livestock and humans (Aranaz et al. 2004) and in Tanzania, a classic example is the illegal hunting of resident and migratory herbivores in protected areas (Loibooki et al. 2002; Magige et al. 2008; Sinclair \& Arcese 1995). The transmission of bovine tuberculosis from wildlife to humans in such cases is by direct contact between infected animals and hunters, either via aerosol contamination when the carcass is opened, through entry of organisms via cuts in the skin or through the alimentary system (Fanning \& Edwards 1991; Georghiou et al. 1989; Robinson et al. 1988).

Tuberculosis in man is generally characterised by loss of weight, weakness, poor appetite, fever, a productive cough, and night sweats. Mycobacterium tuberculosis is the most common cause of human TB, however an unknown proportion of cases occur due to M. bovis (Acha \& Szyfres 1987) at least partly because it is impossible to distinguish tuberculosis infection caused by M. bovis from M. tuberculosis from clinical signs alone. Bovine tuberculosis (BTB) is often subclinical; when present, clinical signs are not specifically distinctive and are characterised by weakness, anorexia, emaciation, dyspnoea, enlargement of lymph nodes, and cough, particularly with advanced tuberculosis (OIE 2009). Pathologically, BTB is characterised by the formation of granulomas (tubercles) that are usually yellowish and either caseous, caseo-calcareous or calcified and are sometimes encapsulated (De Lesle et al. 2002). However, in disseminated cases, multiple small granulomas may be found in numerous organs such as female genitalia (http://www.cfsph.iastate. edu). Mycobacterium bovis may present as extra pulmonary tuberculosis often as cervical lymphadenitis (Kleeberg et al. 198 4; Mfinanga et al. 2004). Based on this premise, M. bovis may present either as pulmonary TB (47\%) or extrapulmonary cases (53\%), whereas $M$. tuberculosis presents as $82 \%$ pulmonary and 18\% extrapulmonary cases (Owendidactic. org, n.d.). Currently, M. bovis accounts for only $1 \%$ of all human TB in developed countries as compared to $10 \%$ in the developing world (Etchechoury et al. 2010). According to a WHO report (2010), there was a significant increase (116.6\%) of extrapulmonary cases of TB reported in Tanzania between 1995 and 2009, which is suggestive of an emerging M. bovis epidemic, however, information on the contributions of M. bovis infection to extra pulmonary cases is very limited and it is possible that these extra cases may also be HIVrelated (Amanfu 2006). The survey conducted by National Tuberculosis and Leprosy Program, Tanzania (NTLP) in 2009 reported that $20.994(37.2 \%)$ out of 64.417 TB patients in Tanzania were co-infected with HIV. According to the World Bank (2010) report on development indicators, the prevalence of HIV ( $\%$ of population aged 15-49) in Tanzania is $5.6 \%$.

Tanzania has the third largest domestic stock population in Africa (after Ethiopia and Sudan). According to the Ministry of Livestock Development and Fisheries (MLDF) national census conducted in $2007 / 2008$, the total numbers were 18.5 million cattle, 13.1 million goats, 3.6 million sheep and 53 million poultry. The livestock production system is a pastoral and agro-pastoral system, where movement of animals searching for pasture and water is unrestricted. The presence of large numbers of livestock in traditional settings and where animals are kept in close contact with little veterinary service contributes to spread of disease. Previous studies conducted in pastoral communities in the Arusha region found that a history of $\mathrm{TB}$ in the family, drinking raw milk, eating raw animal products, poor ventilation and having poor knowledge concerning transmission of tuberculosis were risk factors for $M$. bovis infection and disease (Mfinanga et al. 2004).

The diagnosis of TB in cattle in Tanzania is done by tuberculin skin testing (TST), meat inspection in abattoirs and rarely by bacteriological or molecular techniques The commonly used diagnostic test for human TB in primary health centres and hospitals is microscopic examination and culture, and speciation are not done routinely (Mfinanga et al. 2004). Although meat is recommended to be abbatoirinspected before entering markets, proper meat inspection is not effectively carried out due to the inadequacy of the veterinary service sector as a result of the withdrawal of public veterinary services. In addition, the recommended test and slaughter policy, a disease control program based on slaughter of positive reactors animals, is not properly implemented (see Figure 1) despite our knowledge that this policy has successfully reduced the prevalence of bovine tuberculosis (Michel et al. 2009). It is only Algeria, Burkina Faso, Cameroon, Morocco, Namibia and South Africa out of 48 countries in Africa that apply a test-and slaughter policy as a control measure and consider bovine tuberculosis as a notifiable disease (Cosivi 1998). The lack of public finances are obstacles in the control of bovine tuberculosis in many countries. In Tanzania, lack of clear policies on how bovine tuberculosis can be controlled and the failure of health authorities to recognise $M$. bovis as cause of tuberculosis hinder the control of the disease (Kazwala et al. 2006).

Few studies have confirmed M. bovis in humans in Tanzania (Kazwala et al. 2001; Mfinanga et al. 2004), however, there is a body of evidence for $M$. bovis infection in man and a description of the relationships between $M$. bovis isolates found in humans and cattle. In their study, Kazwala et al. (2001) found that M. bovis isolates from man had a $70 \%-$ $80 \%$ genetic relatedness to those found in cattle, arguably suggesting an infection and evolutionary relationship between them. Mycobacterium bovis infection in man has also been reported in other countries in Africa including Nigeria, Zaire and Egypt (Cosivi 1998; Idrisu et al. 1977; Idigbe et al. 1986; Nafeh et al. 1992). 
This paper aims to review the current situation of $M$. bovis infection in animals and discuss the zoonotic importance of M. bovis in Tanzania. The paper also highlights the burden of tuberculosis, risk factors for infection, communities' knowledge on prevention of the disease and challenges to its control in order to safeguard the human and animal population in Tanzania.

\section{Distribution of bovine tuberculosis in animals in Tanzania}

Mycobacterium bovis was demonstrated in Tanzania for the first time in 1952 (Markham 1952). Thereafter, it has been isolated from livestock, wildlife and humans. The prevalence of $M$. bovis in cattle varies between districts, with more infection in older cattle than yearlings and calves (Kazwala et al. 2001). Variation in M. bovis infection in different geographical areas of the country suggests that there are M. bovis infection foci (or hotspots). Shirima et al. (2003) suggested that many factors could contribute to M. bovis foci, including the presence of mycobacteria in the environment, management practices where animals are extensively grazed and overcrowded at watering points and auction markets. According to Cleveland et al. (2007), flooding has also been suggested as a propagating factor of $M$. bovis in the environment.

Reports from several studies that have been conducted in various districts have reported $M$. bovis infection in livestock as well as wildlife. The prevalence of presumed M. bovis infection determined by using a single intradermal comparative tuberculin test (SICTT) was $1.7 \%(n=181)$ and $0.4 \%(n=259)$ in Kibaha and Morogoro respectively (Mdegela et al. 2004) (Table 1). Durnez et al. (2009) reported a prevalence of $2.4 \%(n=728)$ M. bovis infection in cattle from 49 herds belonging to extensive and intensive management systems. The prevalence of $M$. bovis infection reported by this study was in same range as demonstrated previously in the same region by Shirima et al. (2003). According to Kazwala et al. (1996), the highest prevalence of $13.3 \%$ M. bovis infection was reported in the Southern Highlands and larger herds of cattle had a higher rate of bovine tuberculosis. The prevalence of M. bovis infection in cattle in other parts of the country are as follows: Shinyanga, Mwanza, Bukoba: 0.2\% in intensively managed farms (Jiwa et al. 1997), Rift valley districts (Babati, Hanang, Mbulu and Karatu) 0.93\% (Kazwala et al. 2001), Manyara region $0.9 \%$ (Cleveland et al. 2007).

The prevalence of $M$. bovis in cattle has been reported to be higher in intensive systems than in pastoral production systems (Shirima et al. 2003). However, in contrast, Durnez et al. (2009) reported a higher prevalence of bovine tuberculosis in the extensive than in an intensive system. Husbandry practices in the country could contribute to the difference in prevalence of $M$. bovis infection in extensive and intensive systems. Free movement of animals, overcrowding in communal grazing areas and watering points might contribute to its spread.
A study by Kazwala and colleagues (2006) reported the similarity of $M$. bovis isolates from different geographical locations, which was attributed to migration of cattle as well as sale to local communities. Uncontrolled movement of cattle together with a decline in service of public sector in the provision of veterinary services impeded disease control programs in Tanzania. The withdrawal of a public veterinary service forced livestock keepers to take the responsibility of treating their own livestock in order to fill this vacuum (ftp. fao.org/docrep/fao).

In Tanzania, M. bovis infections have been confirmed in a number of wildlife species including buffalo (Syncerus caffer), African civet (Civettictis civetta, $n=1$ ), lion (Panthera leo), wildebeest (Connochaetes taurinus), topi (Damaliscus lunatus) and lesser kudu (Tragelaphus imberbis) (Table 2). Of particular note, $M$. bovis has been recovered from apparently healthy wildebeest that did not show lesions at post-mortem (Cleveland et al. 2005). These reports are not comprehensive surveys and little information is available on the disease status in wildlife. Analysis of serum samples by using Enzyme Immunoassay (EIA) detected $M$. bovis antibodies in $4 \%$ of Serengeti lions, $6 \%(n=17)$ buffalo (Syncerus caffer) in Tarangire and $2 \%(n=41)$ wildebeest in the Serengeti (Cleveland et al. 2005). It is important to note that the WHO recently issued a statement on the unreliability of serology to diagnose TB and these results are thus at best likely to be a significant underestimate and quantitatively inaccurate.

\section{Countrywide survey of Mycobacterium bovis infection in humans}

Tuberculosis accounts for approximately 6\% of all deaths and $8 \%$ of all diseases in humans (NTLP 2007). However, the contribution of M. bovis to human tuberculosis in Tanzania is unknown, owing to the absence of efforts in most laboratories in hospitals and health centres to differentiate between the species of the M. tuberculosis complex. Despite the lack of data, according to Kazwala et al. (2001), M. bovis infection is considered as a pathogen of concern to people living in rural areas. In many developed countries, human TB caused by $M$. bovis accounts for around $1 \%$ of all TB cases, and sporadic cases occur either in elderly people by reactivation of ancient infections or in immigrants from countries where bovine TB has not been eradicated (De la Rua-Domenech 2006; Etchechoury et al. 2010). In the developing world the contribution of $M$. bovis to human tuberculosis is higher and account for an estimated $10 \%$ of all TB cases (Cousins et al. 1999; Etchochoury et al. 2010). Shitaye et al. (2007) reported that $M$. bovis infection in man depends on the prevalence of the disease in cattle, socioeconomic conditions, consumer habits, food hygiene practices and medical prophylaxis measures.

Human tuberculosis due to $M$. bovis is mostly the result of transmission from cattle to man and in many cases results into extrapulmonary manifestation (Cosivi 1998; Daborn et al., 1997; Kazwala et al. 2001; Mfinanga et al. 2004; Amanfu et al. 2006; Munyeme \& Munang'andu 2011). It 
has been suggested that $M$. bovis infection in man increases proportionately to the total number of TB cases and that HIV is a major factor for development of active TB disease (Cosivi 1998). In developing countries M. bovis infection in humans is also increasing due to the lack of control and diagnostic measures, and pasteurisation of milk (Etter et al. 2006). Thus there is every reason to be seriously concerned that the HIV pandemic will result in an increase of human tuberculosis due to $M$. bovis, and a greater degree of transmission of infection to other humans and to animals could well occur. Information on cross transmission of M. bovis infection between livestock, wildlife and man in Tanzania is limited. This situation is similar to that of other developing countries where M. bovis infection in man is almost certainly underreported (Cosivi et al. 1998; Munyeme \& Munang'andu 2011) due to the lack of diagnostic facilities to distinguish tuberculosis caused by M. bovis and M. tuberculosis.

In Africa, consumption of raw fresh milk and improperly cooked or raw meat, and the attitude of some communities which regard bushmeat (poached or hunted wildlife) as a cheap source of protein, represents one of the major risk factors for humans with respect to infection with $M$. bovis (Aranaz et al. 2004; Etter et al. 2006). Kazwala et al (1998) found that out of 805 milk samples that were collected, 31 $(3.9 \%)$ were positive for mycobacteria. In this study, atypical mycobacteria represented with $87 \%$ of the positive samples, however, $6.5 \%$ contained M. bovis. Whilst these samples represent a minority of the positives, the results show that raw milk is a threat to public health. Moreover, Durnez et al. (2009) reported a high prevalence of $M$. bovis and recovered atypical mycobacteria isolates from milk samples in and around Morogoro, Tanzania, and concluded that the populace, especially cattle owners in an extensive system, should be educated concerning bovine tuberculosis. The high level presence of atypical mycobacteria in milk also poses a danger to immunocompromised individuals, especially HIV and AIDS patients.

Mfinanga et al. (2004), in their study in the Arusha region, northern Tanzania, investigated 457 biopsy specimens, of which 65 (14.2\%) were positive on culture for mycobacteria. In this study, the proportion of atypical mycobacteria was $31(47.7 \%)$ compared to $7(10.8 \%)$ M. bovis, and $27(41.5 \%)$ M. tuberculosis. They concluded that atypical mycobacteria were more common than M. tuberculosis and therefore HIV and raw milk are major risk factors identified for M. bovis and non-tuberculous mycobacterial adenitis.

The finding that atypical mycobacteria are common was confirmed in a study by Durnez et al. (2011), in Morogoro, Tanzania, where $7.3 \%$ of 645 terrestrial small mammals sampled in cattle farms were positive for atypical mycobacteria. A high proportion of the atypical mycobacteria were recovered in insectivores as opposed to rodents. Insectivores feed on insects that spend most of their time in the ground. The recovery of atypical mycobacterium from this source is not surprising perhaps, since mycobacteria are well known environmental and soil dwelling microbes. What is important in this work is that Durnez et al. (2011) established a direct correlation between the proportion of atypical mycobacterium in reacting and non-reacting tuberculin farms, complicating the interpretation of tuberculin skin testing (TST) results.

Mycobacterium bovis is one of the well-known causative agents of human extra-pulmonary tuberculosis. This situation prevails in Tanzania, where an early study (Daborn et al. 1997), showed that seven out of nineteen lymph node biopsies from suspected extra-pulmonary tuberculosis patients were infected with M. tuberculosis and four with M. bovis. In most developing countries, the extent of human tuberculosis due to $M$. bovis and the frequency of $M$. bovis extra-pulmonary tuberculosis is not known (Chen et al. 2009; Cosivi 1998). However, between 1995 and 2009, the number of reported extra-pulmonary TB cases increased from 6195 to 13417 in Tanzania (WHO 2010, see Table 3), which is in all likelihood an underestimate (Kazwala et al. 2001). The available literature shows that $M$. bovis infections are correlated with people who keep large numbers of cattle (Kazwala 1996) and most cases of extra-pulmonary TB were found in regions with a high proportion of cattle to humans (Kazwala et al. 1993). A WHO (2006) zoonotic survey reported the following extrapulmonary cases in several regions with a high population of cattle in Tanzania; Arusha (30\%), Mbeya (28.1\%), Iringa (27.3\%), Shinyanga (19.8\%), Mara (19.7\%), Dodoma (19.4\%) and Mwanza region (10.8\%). A study conducted by Mfinanga et al. (2004) found that a disproportionately high number of mycobacterial adenitis was found in subsistence farmers and livestock keepers in Arusha and Mbeya region which is suggestive of cross transmission of M. bovis.

A high proportion of cattle are kept in traditional settings in rural areas where knowledge regarding $M$. bovis infection is generally minimal (Mfinanga et al. 2004). According to Pušić et al. (2008), the persistence of bovine tuberculosis is mostly linked to the traditional extensive breeding system and freeranging cattle.

Mycobacterium bovis is resistant to pyrazinamide, one of the four first line TB antibiotics and prognosis is often poor (WHO 2010). Given this scenario, it is not surprising that multidrug-resistant strains (MDR) of $M$. bovis have been detected in the USA (Bouvet et al. 1993) and Spain (Guerrero et al. 1997; Rivero et al. 2001).

A study conducted in Tanzania reported genetic relatedness of $M$. bovis isolates in man to those found in cattle (Kazwala et al. 2006). These authors found one strain of M. bovis from a human patient in Arusha region that had the same genotype as $M$. bovis from cattle within the same geographical area.

\section{Risk factors for Mycobacterium bovis infection and disease in humans}

The risk factors for bovine tuberculosis are similar in different geographical areas. According to a study conducted in pastoral communities in the northern part of Tanzania, the risk factors for bovine tuberculosis in man were found to 
be traditional practices such as sleeping in the same house as animals, lack of knowledge regarding the disease and its risks, HIV and AIDS, raw milk consumption and poor ventilation of houses (Mfinanga et al. 2004). In sub-Saharan Africa, active competition between large-scale commercial food enterprises and smaller, less regulated farmers who frequently ignore safety standards for hygiene and product quality, increases the risk of zoonotic tuberculosis (Etter et al. 2006).

Consumption of raw fresh milk is also a risk factor for bovine tuberculosis. Mdegella et al (2004) and colleagues in their study in Morogoro and Kibaha districts concluded that despite the low prevalence of tuberculosis in milk in the study herds, milk consumers are at high risk of being infected with the disease and insisted that farmers should be educated about the risk of bovine tuberculosis and associated health risks. Mfinanga et al. (2003) in their study on the role of livestock keeping in tuberculosis trends in pastoral communities in Babati, Hanang, Mbulu and Karatu districts in the Arusha region, found that all ethnic groups possessed habits and beliefs that increased the risk of being infected with both bovine and human tuberculosis.

In their study, Mdegella et al. (2004) found that $14 \%$ of milk samples $(n=109)$ were positive for atypical mycobacteria. In addition, Mfinanga et al. (2004) found that several activities, including handling animals and animal products, specifically milking, herding cattle and goats, hunting, slaughtering, handling skins and hides, moving cow dung and plastering walls with dung or mud, might increase risk of zoonotic tuberculosis.

\section{Role of husbandry practice in transmission of bovine tuberculosis}

Husbandry practices in Tanzania are divided into three categories, namely, extensive, intensive and semi-intensive systems. The extensive system is traditional and the most popular husbandry practice, and is the main source of milk and meat for Tanzania but receives very little attention from veterinary services. The extensive farming system is practised mostly in rural areas where animals share grazing land and watering points. Most of the cattle kept in Tanzania are Zebu (Bos indicus) which are relatively resistant to diseases (Frankel \& Soule 1981; Wambura et al. 1998). The intensive systems are usually dairy and pig farms which are located in periurban areas and are intended for milk and pork production. In these systems, animals are frequently kept indoors and fed complete rations, but in some cases they are grazed outside to supplement feeding.

A single comparative intradermal tuberculin test (SCITT) survey conducted in different farming systems in the eastern zone of Tanzania found that bovine tuberculosis occurred both in intensive and pastoral farming systems, with significantly higher prevalence in the intensive system than in pastoral systems (Shirima et al. 2003). This could be attributed to husbandry practices in especially dairy cattle that are confined indoors, where close contact between animals and lack of ventilation increase chances of disease transmission. However, this is contrary to results presented by Durnez et al. (2009) in a more recent study, who showed that $M$. bovis infection in extensive farming systems was higher than intensive systems. The contradiction of infection rate in different farming systems could be explained by considering the management practices of each farming practice, or that systems have changed over time. In the extensive system, free movement of cattle which share grazing land and watering points facilitate disease transmission. Poor animal housing and drainage systems designs in intensive farm systems and water supply are key elements that could play a big role in diseases transmission (Pool 1945).

\section{Challenges for control of bovine tuberculosis in cattle in Tanzania}

In Tanzania, M. bovis is considered as a neglected disease and it has not been assigned as a notifiable disease (Kazwala et al. 2006). When it comes to disease control, most resources are directed to notifiable diseases such as contagious bovine pleuropneumonia, African swine fever, rinderpest, contagious caprine pleuropneumonia and Rift Valley fever.

Extensive husbandry practices are widespread and cattle move from one place to another searching for grazing and watering points. This situation is exacerbated during drought, when nomadic tribes move and establish temporary settlements in areas where grazing land and water are available. Bovine tuberculosis could be eradicated at the national level if attention is given at policy level. According to Collins (2006), the success of a national eradication programme, include a clear identification of the goals, of the policies that guide actions and of the sequences of actions that are required within the programme to accomplish these goals. Eradication is possible if movement of cattle is controlled, if there is compulsory testing of all cattle within specified intervals, if positive reactors are removed (slaughtered in a controlled manner), if compensation is provided to farmers for all positive reactors, if compulsory identification is done, and if there is establishment and maintenance of disease free areas, and sufficient funds and manpower to fulfil the task are provided (http://www.pathobiologics.org/ivphc/ ref/MCCRINDLE_SHANGAI_2006.pdf). However, this has been impossible for most developing countries because of cost implications. In The Netherlands and Australia, eradication of bovine tuberculosis was successfully achieved due to the practical involvement of farmers as stakeholders (Collins 2006). However, the success of bovine tuberculosis eradication programmes in developed countries was achieved at a time when herds were smaller, and the intensity and demands of production were lower (Collins 2006).

The presence of maintenance hosts in wildlife populations also impede bovine tuberculosis eradication programs (Etter et al. 2006). White et al. (2008) reported that the presence of multiple hosts for bovine tuberculosis complicate control measures not only because of resistance variation between 
the different host species but also because of ecological and behavioural differences. The African buffalo is a known maintenance host of bovine tuberculosis. Aerosol transmission of $M$. bovis within buffalo herds is favoured by their social behaviour (Michel et al. 2006) and can be transferred to domestic cattle by intermingling. Globally, the presence of wildlife maintenance hosts threatens M. bovis eradication programs (Etter et al. 2006). In Tanzania, the National policy on control of wildlife diseases in protected areas is to leave nature to take its own course. There are very few circumstances where treatment or intervention occurs or is allowed. Wildlife immunisation is not allowed in National Parks, Game Reserves and Game Controlled Areas. In circumstances where bovine tuberculosis control in wildlife is not practised and communities around protected area conduct illegal bush hunting in wildlife areas, the risk for cross-transmission of diseases to livestock and humans remain very high.

According to Cross and Gertz (2006) vaccination could potentially control bovine tuberculosis, but combining vaccination and culling of infected animals is a more attractive management option. This is perhaps of little importance for TB control at this stage, since there is no evidence that vaccination against TB would be successful, even if attempted. Furthermore, vaccination of cattle against bovine tuberculosis or improvement in tuberculosis testing procedures will have no effect on wildlife tuberculosis prevalence (Kao et al. 1997). In Britain, culling of a maintenance host of bovine tuberculosis, the badgers (Meles meles), increased the prevalence of bovine tuberculosis in the cattle population because of ecological and social disturbances of the badger populations (White et al. 2008). Thus, the reduction of transmission risk between species is not a simple matter.

However, a reduction of or minimising contact between wildlife and livestock could serve as a priority for future management of the disease in Tanzania. Collins and Grange (1983) reported that 'it is axiomatic that no control measures against transmissible diseases can be totally effective unless all reservoirs of the causative agent can be eliminated'. As in other parts of the world, the challenge facing the control of tuberculosis is the lack of an effective vaccine. The current TB vaccine, $M$. bovis Bacille Calmette-Guérin (BCG) provides little or no protection against pulmonary tuberculosis in cattle and man (Hogartha et al. 2005). Nevertheless, bovine tuberculosis could be controlled if there are sound control measures such as regular skin testing and removal of reactors, meat inspection in abattoirs, restriction of cattle movements (Pušić et al. 2008).

\section{Conclusion}

There is a remarkable paucity of information available on the zoonotic importance of bovine tuberculosis in humans, particularly in developing countries such as Tanzania. The lack of diagnostic facilities to distinguish between M. bovis and M. tuberculosis is a challenge. Moreover, high proportions of atypical mycobacteria in clinical specimens indicate a widespread environmental occurrence of these organisms, which further complicates accurate diagnosis. Lack of clear policies and implementation regarding control of bovine tuberculosis in cattle impedes control of the disease. Widespread evidence of $M$. bovis infection in animals and humans should be an alarm sign for medical and veterinary health professionals and government bodies. This illustrates the importance of the 'One Health Concept' that can bring together medical and veterinary practitioners as an important tool to fight diseases of public health and economic importance.

\section{Acknowledgement}

The authors would like to thank the Southern African Centre for Infectious Diseases Surveillance (SACIDS) funded by the Welcome Trust for support. Prof Mark Rweyemamu, The Director SACIDS is acknowledged for his ideas and encouragement in writing of the manuscript. The SACIDS Collaborative institutions in the United Kingdom (Royal Veterinary College and London School of Hygiene and Tropical Medicine) through London International Development Centre (LIDC) are also acknowledged for their support during a stay in the UK.

\section{Competing interest}

The authors declare that they have no financial or personal relationship(s) which may have inappropriately influenced them in writing this paper.

\section{Authors' contributions}

B.Z.K. (Muhimbili University of Health and Allied Sciences) reviewed the literature, drafted and wrote the manuscript. E.V.M. (Muhimbili University of Health and Allied Sciences) contributed to the drafting and critical review of the manuscript. S.K. (Royal Veterinary College) made conceptual contribution and critical review of the manuscript. R.D.F. (Tanzania Wildlife Research Institute) made conceptual contribution and significant review of the manuscript. G.S.K. (Kilimanjaro Clinical Research Institute) assisted in critical review of the manuscript and made contribution on preparation of the manuscript. P.G.F. (London School of Hygiene and Tropical Medicine) made conceptual contribution and critical review of the manuscript. J.D.K. (Tanzania Wildlife Research Institute) contributed to the drafting, conceptualization and critical review of the manuscript. P.v.H. (University of Stellenbosch) made conceptual contribution and critical review of the manuscript. M.I.M. (Muhimbili University of Health and Allied Sciences) made conceptual contribution and critical review of the manuscript. All authors have read and approved the final manuscript. 


\section{References}

Acha, P.N. \& Szyfres, B., 1987, Zoonotic tuberculosis, in Zoonoses and communicable diseases common to man and animals, 2nd edn., Pan American Health Organisation/World Health Organisation, Scientific publication No 503 Washington.

Amanfu, W., 2006, 'The situation of tuberculosis and tuberculosis control in animals of economic interest', Tuberculosis 86, 330-335. http://dx.doi.org/10.1016/j. tube.2006.01.007

Aranaz, A., Juan, L., Montero, N., Sanchez, C., Galka, M., Delso, C. et al., 2004, 'Bovine tuberculosis (Mycobacterium bovis) in wildlife in Spain', Journal of Clinical Microbiology 42, 2602-2608. http://dx.doi.org/10.1128/JCM.42.6.2602-2608.2004

Bouvet, E., Casalino, E., Mendoza-Sassi, G., Lariven S., Vallée E., Pernet M. et al., 1993, 'Nosocomial outbreak of multidrug-resistant Mycobacterium bovis among
HIV-infected patients: A case control study', AIDS 7, 1453-1460. http://dx.doi. HIV-infected patients: A case control study,
org/10.1097/00002030-199311000-00008

Chen, Y., Chao, Y., Deng, Q., Liu, T., Xiang, J., Chen, J. et al., 2009, 'Potential challenges to the stop TB plan for humans in China; Cattle maintain M. bovis and $M$. to the stop, TB plan for humans in China; Cattle maintain M. bovis and M.
tuberculosis', Tuberculosis 89, 95-100. http://dx.doi.org/10.1097/00002030tuberculosis', Tuberc

Cleaveland, S., Mlengeya, T., Kazwala, R.R., Michel, A., Kaare, M.T., Jones, S.L. et al. 2005, 'Tuberculosis in Tanzanian wildlife', Journal of Wildlife Diseases 41, 446-453.

Cleaveland, S., Shaw, D.J., Mfinanga, S.G., Shirima, G., Kazwala, R.R., Eblate E. et al., 2007, 'Mycobacterium bovis in rural Tanzania, risk factors for infection in human and cattle populations', Tuberculosis 87, 30-43. http://dx.doi.org/10.1016/j. tube.2006.03.001

Collins, C.H. \& Grange, J.M., 1983, 'The bovine tubercle bacillus', Journal of Applied Bacteriology 55, 13-29. http://dx.doi.org/10.1111/j.1365-2672.1983.tb02643.x

Collins, J.D., 2006, 'Tuberculosis in cattle: Strategic planning for the future', Veterinary Microbiology 112, 369-381. http://dx.doi.org/10.1016/j.vetmic.2005.11.041

Cosivi, O., Grange, J.M, Daborn, C.J., Rviglione, M.M., Fujikura, T., Cousins, D. e al., 1998, 'Zoonotic tuberculosis due to Mycobacterium bovis in developing countries', Emerging Infectious Diseases 4, 59-70. http://dx.doi.org/10.3201/ eid0401.980108

Cousins, D.V., Williams, S.N. \& Dawson, D.J., 1999, 'Tuberculosis due to Mycobacterium bovis in the Australian population, DNA typing of isolates, 1970-1994', The International Journal of Tuberculosis and Lung Disease 3, 722-731.

Cross, P.C. \& Getz, W.M., 2006, 'Assessing vaccination as a control strategy in an ongoing epidemic', 'Bovine tuberculosis in African buffalo', Ecological Modelling 96, 494-504. http://dx.doi.org/10.1016/j.ecolmodel.2006.02.009

Daborn, C.J., Grange, J.M. \& Kazwala, R.R., 1996, 'The bovine tuberculosis cycleAn African perspective', Society for Applied Bacteriology symposium series 25 , 27s-32s. http://dx.doi.org/10.1111/j.1365-2672.1996.tb04595.x

De la Rua-Domenech, R., 2006, 'Human Mycobacterium bovis infection in the United Kingdom: Incidence, risks, control measures and review of the zoonotic aspects
of bovine tuberculosis', Tuberculosis 86, 77-109. http://dx.doi.org/10.1016/j. of bovine tuberculo

De Lesle, G.W., Bengis, R.G., Schmitt, S.M. \& O' Brien, D.J., 2002, 'Tuberculosis in freeranging wildlife: detection, diagnosis and management', Revue Scientifique et ranging wildlife: detection,
Technique (OIE) 21, 317-334.

Durnez, L., Eddyani, M., Mgode, G.F., Katakweba, A., Katholi, R.I., Kazwala R.R. et al., 2008, 'First detection of mycobacteria in African rodents and insectivores, using stratified pool screening', Applied and Environmental Microbiology 74, 768-773. http://dx.doi.org/10.1128/AEM.01193-07

Durnez, L., Katakweba, A., Sadiki, H., Katholi, C.R., Kazwala, R.R., Machang'u, R.R. et al., 2011, 'Mycobacteria in terrestrial small mammals on cattle farms in Tanzania', Veterinary Medicine International. http://dx.doi.org/10.4061/2011/495074

Durnez, L., Sadiki, H., Katakweba, A., Machang'u, R.R., Kazwala, R.R., Leirs, H. et al., 2009, 'The prevalence of Mycobacterium bovis-infection and typical mycobacterioses in cattle in and around Morogoro, Tanzania', Tropical Anima Health and Production 41, 1653-1659. http://dx.doi.org/10.1007/s11250-0099361-4

Etchechoury, I., Echeverria Valencia, G., Morcillo, N., Sequeira, M.D., Imperiale, B. López, M. et al., 2010, 'Molecular typing of Mycobacterium bovis Isolates in Argentina: First description of a person-to-person transmission case', Zoonoses Public Health 57, 375-381. http://dx.doi.org/10.1111/j.1863-2378.2009.01233.x

Etter, E., Donald, P., Jori, F., Caron, A., Goutard, F. \& Roger, F., 2006, 'Risk analysis and bovine tuberculosis, a re-emerging zoonosis', Annals of the New York Acadamy of Sciences 1081, 61-73. http://dx.doi.org/10.1196/annals.1373.006

Fanning, A. \& Edwards, S., 1991, 'Mycobacterium bovis infection in human beings in contact with elk (Cervus elaphus) in Alberta, Canada', Lancet 338, 1253-1255. http://dx.doi.org/10.1016/0140-6736(91)92113-G

Figueroa-Munoz, J. \& Ramon-Pardo, P., 2008, 'Tuberculosis control in vulnerable groups', Bulletin of the World Health Organization, Part issues 86, 657-736.

Frankel, O.H. \& Soule, E.M., 1981, 'Conservation and Evolution', Cambridge University Press, Cambridge, USA

Georghiou, P., Patel, A.M. \& Konstantinos, A., 1989, 'Mycobacterium bovis as an occupational hazard in abattoir workers', Australian and New Zealand Journal of Medicine 19, 409-410. http://dx.doi.org/10.1111/j.1445-5994.1989.tb00289.x

Grange, J.M. \& Collins, C.H., 1987, 'Bovine tubercle bacilli and disease in animals and man', Epidemiology and Infection 99, 221-234. http://dx.doi.org/10.1017/ S0950268800067686
Guerrero, A., Cobo, J., Fortún, J., Navas, E., Quereda, C., Assensio, A. et al., 1997, 'Nosocomial transmission of Mycobacterium bovis resistant to 11 drugs in people with advanced HIV-1 infection', Lancet 350, 1738-1742. http://dx.doi. people with advanced HIV-1 infection,
org/10.1016/S0140-6736(97)07567-3

Hogarth, P.J., Logan, K.E., Vordermeier, H.M., Singh, M., Hewinson, R.G. \& Chambers, M.A., 2005, 'Protective immunity against Mycobacterium bovis induced by vaccination with Rv3109c-a member of the esat-6 gene family', Vaccine 23 vaccination with Rv3109c-a member of the esat-6 gene fam
2557-2564. http://dx.doi.org/10.1016/j.vaccine.2004.11.030

Idigbe, E.O., Anyiwo, C.E. \& Onwujekwe, D.I., 1986, 'Human pulmonary infections with bovine and atypical mycobacteria in Lagos, Nigeria', Journal of Tropical Medicine and Hygiene 89, 143-8.

Idrisu, A. \& Schnurrenberger, P., 1997, 'Public health significance of bovine tuberculosis in four northern states of Nigeria, a mycobacteriologic study', Nigerian Medical Journal 7, 384-7.

Jiwa, S.H.F., Kazwala, R.R., Aboud, A.A.O. \& Kalaye, W.J., 1997, 'Bovine tuberculosis in the Lake Victoria zone of Tanzania and its possible consequences for human health in the HIV/AIDS era', Veterinary Research Communication 21, 533-539. http://dx.doi.org/10.1023/A'1005900929479

Kao, R.R., Robberts, M.G. \& Ryan, T.J., 1997, 'A model of bovine tuberculosis control in domesticated cattle herds', Proceedings. Biological Sciences/The Royal Society 264, 1069-1076

Kazwala, R.R, Daborn, C., Sharp, J.M., Kambarage, D.M., Jiwa, S.F. \& Mbembeti, N.A., 2001, 'Isolation of Mycobacterium bovis from human cases of cervical adenitis in Tanzania, a cause for concern?', International Journal of Tuberculosis and Lung Diseases 5, 87-91.

Kazwala, R.R., 1996, 'Molecular epidemiology of bovine tuberculosis in Tanzania', PhD thesis, Edinburgh, University of Edinuburgh.

Kazwala, R.R., Catley, A.P., Daborn, C.J. \& Kambarage, D.M., 1993, 'The zoonotic implications of bovine tuberculosis in Tanzania', in P.M. Msolla \& S.I.K. Kimera (eds.), Proceedings of the 10th Tanzania Veterinary Association scientific conference. Morogoro, Tanzania: Tanzania Veterinary Association 1993, 67-81.

Kazwala, R.R., Daborn, C.J., Kusiluka, L.J.M., Jiwa, S.F.H., Sharp, J.M. \& Kambarage, D.M., 1998, 'Isolation of Mycobacterium species from raw milk of pastoral cattle of the Southern Highlands of Tanzania', Tropical Animal Health and Production 30 233-239. http://dx.doi.org/10.1023/A:1005075112393

Kazwala, R.R., Daborn, C.J., Kusiluka, L.J.M., Jiwa, S.F.H., Sharp, J.M. \& Kambarage, D.M., 1998, 'Isolation of Mycobacterium species from raw milk of pastoral cattle of the Southern Highlands of Tanzania', Tropical Animal Health and Production 30 233-239. http://dx.doi.org/10.1023/A:1005075112393

Kazwala, R.R., Kambarage, D.M., Daborn, C.J, Nyange, J., Jiwa, S.F.H. \& Sharp, J.M., 2001 , 'Risk factors associated with the occurrence of bovine tuberculosis in cattle in the Southern Highlands of Tanzania', Veterinary Research Communications 25 609-614. http://dx.doi.org/10.1023/A:1012757011524

Kazwala, R.R., Kusiluka, L.J.M., Sinclair, K., Sharp, J.M. \& Daborn, C.J., 2006, 'The molecular epidemiology of Mycobacterium bovis infections in Tanzania', Veterinary Microbiology 112, 201-210. http://dx.doi.org/10.1016/j.vetmic.2005.11.026

Kleeberg, H.H., 1984, 'Human tuberculosis of bovine origin in relation to public health', Revue Scientifique et Technique (OIE) 3, 11-32.

Loibooki, M., Hofer, H., Campbell, K.L.I. \& East, M.L., 2002, 'Bushmeat hunting by communities adjacent to the Serengeti National Park, Tanzania, the importance of livestock ownership and alternative sources of protein and income', Environmental Conservation 29, 391-398. http://dx.doi.org/10.1017/S0376892902000279

Magige, F.J., Holmern, T., Stokke, S., Mlingwa, C. \& Røskaft, E., 2008, 'Does illegal hunting affect density and behaviour of African grassland birds? A case study on ostrich (Struthio camelus)', Biodiversity and Conservation 18, 1361-1373. http:// dx.doi.org/10.1007/s10531-008-9481-6

Markham, A.E.G., 1952, 'Bovine tuberculosis in the Southern Highlands Province of Tanganyika', PhD thesis, University of London, UK.

Mdegela, R.H., Kusiluka, L.J., Kapaga, A.M., Karimuribo, E.D., Turuka, F.M., Bundala, A. et al., 2004, 'Prevalence and determinants of mastitis and milk-borne zoonoses in smallholder dairy farming sector in Kibaha and Morogoro districts in Eastern Public Health 51, 123-128. http://dx.doi.org/10.1111/j.1439-0450.2004.00735.x

Mfinanga, G.S., Morkve, O., Kazwala, R.R., Cleaveland, S., Sharp, J.M., Shirima, G.M. et al., 2003, 'Tribal differences in perception of tuberculosis, a possible role in tuberculosis control in Arusha,
and Lung Disease 7, 933-941.

Mfinanga, S.G.M., Morkve, O., Kazwala, R.R., Cleaveland, S., Sharp, M.J., Kunda, J. et al., 2004, 'Mycobacterial adenitis, role of Mycobacterium bovis, non tuberculous
mycobacteria, HIV infection, and risk factors in Arusha, Tanzania', East African mycobacteria, HIV infection, and risk factors in Arusha, Tanzania', East Afri
Medical Journal 81, 171-178. http://dx.doi.org/10.4314/eamj.v81i4.9150

Michel, A.L., Bengis, R.G., Keet, D.F., Hofmeyr, M., De Klerk, L-M., Cross, P.C. et al. 2006, 'Wildlife tuberculosis in South African conservation areas, implications and
challenges', Veterinary Microbiology 112, 91-100. http://dx.doi.org/10.1016/j. challenges', Veterinary

Michel, A.L., Coetzee, M.L., Keet, D.F., Maré, L., Warren, R., Cooper, D. et al., 2009, 'Molecular epidemiology of Mycobacterium bovis isolates from free ranging
wildlife in South African game reserves', Veterinary Microbiology 133, 335-343. wildlife in South African game reserves', Veterin
http://dx.doi.org/10.1016/j.vetmic.2008.07.023

Ministry of Livestock Development and Fisheries (MLDF) (National livestock census sample statistics 2007 - 2008, Agricultural policy, Dar es Salaam, Tanzania.

Munyeme, M. \& Munang'andu, H.M.A., 2011, 'Review of bovine tuberculosis in the Kafue basin ecosystem', Veterinary Medicine International. 
Nafeh, M.A., Medhat, A., Abdul-Hameed, A-G., Ahmad, Y.A., Rashwan, N.M. \& Strickland, G.T., 1992, 'Tuberculous peritonitis in Egypt, the value of laparoscopy
in diagnosis', The American Journal of Tropical Medicine and Hygiene 47, 470-477.

National Tuberculosis and Leprosy Programme Tanzania (NTLP), 2009, Annual report 1995, Ministry of Health, Dar es Salaam, Tanzania.

National Tuberculosis and Leprosy Programme Tanzania (NTLP), 2007, Annual report 1995, Ministry of Health, Dar es Salaam, Tanzania.

OIE Terrestrial Manual, 2009, Bovine Tuberculosis, World assembly of delegates of the OIE in May 2009, Chapter 2.4.7.

Pool, W.A., 1945, 'The Eradication of Tuberculosis in Cattle, Section of comparative medicine, Disease in relation to animal husbandry', Proceedings of the Roya Society of Medicine 39, 77-82.

Pušić, A., Savić-Jevdenić, S., Lalošević, D., Bugarski, D., Prodanov, J. \& Grgić, Z., 2008 'An epidemiological evaluation of bovine tuberculosis in South Backa region of Vojvodina Province', Lucrări Stiintifice Medicină Veterinară, vol. xli, Timisoara.

Rivero, A., Márquez, M., Santos, J., Pinedo, A., Sánchez, M.A., Esteve, A., Samper, S \& Martin, C., 2001, 'High rate of tuberculosis reinfection during a nosocomial \& Martin, C., 2001, 'High rate of tuberculosis reinfection during a nosocomial
outbreak of multidrug-resistant tuberculosis caused by Mycobacterium bovis strain outbreak of multidrug-resistant tuberculosis caused by Mycobacterium bovis strain
$\mathrm{B}^{\prime}$, Clinical Infectious Disease 32, 159-161. http://dx.doi.org/10.1086/317547

Robinson, P., Morris, D. \& Antic, R., 1988, Mycobacterium bovis as an occupational hazard in abattoir workers', Australian and New Zealand Journal of Medicine 18 701-703. http://dx.doi.org/10.1111/j.1445-5994.1988.tb00156.x
Shirima, G.M., Kazwala, R.R. \& Kambarage, D.M., 2003, 'Prevalence of bovine tuberculosis in cattle in different farming system in Tanzania', Preventive Veterinary Medicine 57, 167-172. http://dx.doi.org/10.1016/S0167-5877(02)00214-3

Shitaye, J.E., Tsegaye, W. \& Pavlik, I., 2007, 'Bovine tuberculosis infection in animal and human populations in Ethiopia: A review', Veterinary Medicine 52, 317-332.

Sinclair, A.R.C. \& Arcese, P., 1995, Serengeti II, 'Dynamics, management, and conservation of an ecosystem', The University of Chicago Press, LTD., London.

Wambura, P.N., Gwakisa, P.S., Silayo, R.S. \& Rugaimukamu, E.A., 1998, 'Breedassociated resistance to tick infestation in Bos indicus and their crosses with Bos Taurus', Veterinary Parasitology $77,63-70$. http://dx.doi.org/10.1016/S0304 4017(97)00229-X

White, P.C.L., Bohm, M., Marion, G. \& Hutchings, M.R., 2008, 'Control of bovine tuberculosis in British livestock - There is no "silver bullet", Trends in microbiology 16, 420-427. http://dx.doi.org/10.1016/j.tim.2008.06.005

World Bank Report, 2010, Development Indicators, viewed on 15 July 2011, from http://data.worldbank.org/news/world-development-indicators-2010-released

World Health Organization (WHO), 2006, 'The Control of Neglected Zoonotic Diseases, A route to Poverty alleviation', Report of a Joint WHO/DFID-AHP Meeting with the participation of FAO and OIE, Geneva, 20 and 21 September 2005, from http://www.int/zoonoses/Report_Sept06.pdf.

World Health Organization (WHO), 2010, Global tuberculosis control, Global, region and country-specific for key indicators, viewed 25 June 2011, from www.who. int/tb/data 